\title{
Nitric Oxide Produced by the Enterocyte Is Involved in the Cellular Regulation of Ion Transport
}

\author{
ROBERTO BERNI CANANI, PIA CIRILLO, VITTORIA BUCCIGROSSI, GIULIO DE MARCO, \\ GIUSEPPE MALLARDO, EUGENIA BRUZZESE, GAETANO POLITO, AND ALFREDO GUARINO
}

Department of Pediatrics, University Federico II, 80131 Naples, Italy [R.B.C., P.C., V.B., G.D.M., G.M., E.B., G.P., A.G.]

\begin{abstract}
The role of nitric oxide (NO) in the intestinal basal ion transport and under conditions of enterotoxin-induced ion secretion is controversial. Namely it is not clear whether NO enhances or counteracts intestinal ion secretion and whether the effects on transport result from a direct interaction with the enterocyte. The cell origin of NO is also unclear. We have tested the hypothesis that NO produced by the enterocyte directly regulates ion transport processes either in basal condition or in response to cholera toxin-induced secretion. Electrical variables reflecting transepithelial ion transport were measured in Caco-2 cell monolayers mounted in Ussing chambers exposed to the NO synthase inhibitor $N \omega$-nitro-L-arginine methyl ester, in the presence or absence of cholera toxin. cAMP concentrations were also measured. NO release was determined by nitrite-nitrate concentration. NO synthase activities were assayed by Western blot analysis. $N \omega$-nitroL-arginine methyl ester had a secretory effect, as judged by increased basal short-circuit current and cAMP concentration. It also increased cholera toxin-induced electrical response and cAMP production. Either cholera toxin or the cAMP analog 8-bromo-cAMP induced a rapidly progressive and $\mathrm{Ca}^{2+}$ dependent increase in NO concentration, suggesting a homeostatic up-regulation of the constitutive form of NO synthase.
\end{abstract}

\section{ABSTRACT}

Western blot analysis showed an increase in constitutive NO synthase enzyme isoform. These results indicate that the enterocyte regulates its own ion transport processes, either in basal condition or in the presence of active secretion, through the activation of a constitutive NO synthase-NO pathway, functioning as a braking force of cAMP-induced ion secretion. (Pediatr Res 54: 64-68, 2003)

Abbreviations
NO, nitric oxide
NOS, nitric oxide synthase
cNOS, constitutive nitric oxide synthase
iNOS, inducible nitric oxide synthase
NO $_{2}^{-} / \mathrm{NO}_{3}{ }^{-}$, nitrite/nitrate
L-NAME, $N \omega$-nitro-L-arginine methyl ester $^{\text {L-NIL, } N \text {-iminoethyl-L-lysine }}$
CT, cholera toxin
G, conductance
$\boldsymbol{I}_{\text {sc }}$, short circuit current
PD, transepithelial potential difference
8Br-cAMP, 8-bromo-cAMP

Intestinal water and electrolyte transepithelial transport is under a complex control by several agents including neurotransmitters, hormones, or paracrine agents (1). There is evidence that NO takes part in the intestinal ion transport processes with an effect that involves the enteric nervous system, the suppression of prostaglandin formation, and the opening of $\mathrm{K}^{+}$channels $(2,3)$.

NO is a gas with a half-life of less than $5 \mathrm{~s}$, rapidly degrading to nitrite and nitrate in the presence of oxygen and

Received January 10, 2002; accepted September 18, 2002.

Correspondence: Alfredo Guarino, M.D., Department of Pediatrics, University "Federico II,” Via S. Pansini, 580131 Naples, Italy; e-mail: alfguari@unina.it

Supported in part by a grant from the Ministero della Sanità, AIDS research project 1999 program 50.c.28, and by a grant from CNR n.94.02505 CT04.

DOI: 10.1203/01.PDR.0000069841.52414.A5 water. NO is produced by a number of cells, including neuronal cells, and released in various organs. Being soluble in both water and lipids, it freely passes into adjacent target cells $(2,4)$. $\mathrm{NO}$ is generated from L-arginine by a family of enzymes, NOS, whose activity can be stereospecifically inhibited by L- but not by $\mathrm{D}$-arginine analogs (5). Two NOS are constantly active in the intestine and are termed cNOS. They include the neuronal NOS (NOS 1) and the endothelial NOS (NOS 3). Both are $\mathrm{Ca}^{2+}$ /calmodulin-dependent, produce small amounts of NO in short burst, and are involved in several homeostatic processes. A third NOS form, which is $\mathrm{Ca}^{2+} /$ calmodulin-independent, is activated by various signal molecules, including proinflammatory cytokines. This latter form, termed iNOS (NOS 2), requires at least $2 \mathrm{~h}$ to be activated, and released $\mathrm{NO}$ can be measured no earlier than 3-4 h after induction. Maximal NO 
production by this mechanism is commonly observed $6-24 \mathrm{~h}$ after induction, and peak concentration lasts $24-72 \mathrm{~h}(2,6,7)$. $\mathrm{NO}$ is thus produced by the enterocyte through both the cNOS and the iNOS forms $(8,9)$.

NO may play a dual role in the intestinal ion transport processes. In physiologic conditions, the basal cNOS activity is implicated in the regulation of the proabsorptive tone in the intestine, but whether this is the result of a direct effect on the enterocyte, or involves a neurologic control of intestinal blood flow, is still not clear $(2,3)$. On the contrary, an overproduction of NO by iNOS in pathologic conditions, such as inflammatory intestinal diseases, results in net ion secretion (1-12).

NO appears to have some role also in stimulated secretion. In animal models, CT-induced fluid secretion was downregulated by NO (2). However, others did not detect any modification in CT-induced fluid secretion after administration of NOS inhibitors or NO donors (13). Recently, Turvill et al. (14) hypothesized that NO has a dual role in CT-induced secretion, acting either as an absorbagogue or as a secretagogue in the rat perfused small intestine, depending on its concentration. These apparently conflicting findings are probably related to the multiple effects of NO, dose-dependent effects, and different experimental models. In the majority of studies, whole intestinal tissue was used, which contains endothelium, neurons, myocytes, mast cells, and leukocytes, all potential sources of NO. This makes it difficult to track the origin and the effects of NO in the enterocyte. The use of intestinal cell lines to study intestinal electrolyte transport would directly address these issues. Indeed, previous studies have identified both iNOS and cNOS forms in cultures of intestinal epithelium, and Caco-2 cell monolayers have been previously used for studying NO production in response to live bacteria (15).

The aim of this study was to test the hypothesis that NO produced by the enterocyte acts as an intracellular regulator of ion transport both in basal conditions and in response to CT-induced ion secretion. We have used an in vitro model, based on Caco-2 cells, previously validated to investigate the regulation of ion transport at the cellular level and NO production (16-18).

\section{METHODS}

Cell culture. Caco-2 cells (code BS-TCL87) were obtained from the Istituto Zooprofilattico Sperimentale (Brescia, Italy). Cells were grown in Dulbecco's Modified Eagle's Medium (DMEM) with a high glucose concentration $(4.5 \mathrm{~g} / \mathrm{L})$ supplemented with $10 \% \mathrm{FCS}, 1 \%$ nonessential amino acids, penicillin $(50 \mathrm{mU} / \mathrm{mL})$, and streptomycin $(50 \mathrm{mg} / \mathrm{mL})$ and were incubated in $5 \% \mathrm{CO}_{2}-95 \%$ air. The medium was changed daily.

Ion transport studies. Cells were grown on uncoated polycarbonate transwell filters as previously described and used for intestinal transport studies at $15 \mathrm{~d}$ postconfluence (16). The filter area was $4.9 \mathrm{~cm}^{2}$. Each filter was mounted in an Ussing chamber (World Precision Instrument, Sarasota, FL, U.S.A.) as a flat sheet between the mucosal and the serosal compartments. Each compartment contained $10 \mathrm{~mL}$ of Ringer's solution with the following composition (in $\mathrm{mM}$ ): $\mathrm{NaCl}, 114 ; \mathrm{KCl}, 10 ; \mathrm{Na}_{2} \mathrm{HPO}_{4}, 1.65$; $\mathrm{NaH}_{2} \mathrm{PO}_{4}, 0.3 ; \mathrm{CaCl}_{2}, 1.25 ; \mathrm{MgCl}_{2}, 1.1 ; \mathrm{NaHCO}_{3}, 15$; glucose,
19. The incubation fluid was gassed with $95 \% \mathrm{O}_{2}-5 \% \mathrm{CO}_{2}$ and maintained at $37^{\circ} \mathrm{C}$ by a thermostat-regulated circulating pump. The following electrical variables were monitored by an automatic voltage-clamp (DVC 1000, World Precision Instrument) as previously described (19), before and after the addition of CT or the NOS inhibitor L-NAME: PD, $I_{\mathrm{sc}}$, and tissue ionic $G . I_{\mathrm{sc}}$ is expressed as microamperes per square centimeter $\left(\mu \mathrm{A} / \mathrm{cm}^{2}\right), G$ as millisiemens per square centimeter $\left(\mathrm{mS} / \mathrm{cm}^{2}\right)$, and PD as millivolts $(\mathrm{mV})$. Caco-2 cell monolayers were exposed to maximal effective doses of CT $\left(6 \times 10^{-8} \mathrm{M}\right)$ added to the mucosal side in the presence or absence of a maximal effective concentration of L-NAME $\left(2 \times 10^{-4} \mathrm{M}\right)$ added to both sides. CT and L-NAME maximal effective concentrations were determined by doseresponse experiments previously performed (data not shown). Cell viability was checked at the end of each experiment by measuring the $I_{\mathrm{sc}}$ increase after the serosal addition of theophylline $(5 \mathrm{mM})$

Intracellular cAMP concentration. cAMP concentration in Caco-2 cells was determined by a commercial kit (Biotrak cAMP assay system; Amersham International, Amersham, U.K.), as previously described (20).

$\mathrm{NO}_{2}{ }^{-} \mathrm{NO}_{3}{ }^{-}$concentration. The combined concentrations of $\mathrm{NO}_{2}{ }^{-}$and $\mathrm{NO}_{3}{ }^{-}$, the degradation products of $\mathrm{NO}$ in the culture medium, were determined by the Griess reaction after nitrate reduction as previously described (21). Total $\mathrm{NO}_{2}{ }^{-} / \mathrm{NO}_{3}{ }^{-}$production is therefore referred to as NO production. Caco-2 cell monolayers were grown on plates and used at $15 \mathrm{~d}$ postconfluence. Experiments were also performed in $\mathrm{Ca}^{2+}$-free Ringer's solution to investigate whether cNOS, which is the $\mathrm{Ca}^{2+}$ / calmodulin-dependent NOS form, rather than the iNOS form was involved. The modified $\mathrm{Ca}^{2+}$-free Ringer's solution had the following composition (in mM): $\mathrm{Na}_{2} \mathrm{HPO}_{4}, 1.65 ; \mathrm{NaH}_{2} \mathrm{PO}_{4}, 0.3$; $\mathrm{NaHCO}_{3}, 15 ; \mathrm{NaCl}, 53 ; \mathrm{KCl}, 10 ; \mathrm{Na}_{2} \mathrm{SO}_{4}, 30.5 ; \mathrm{MgCl}_{2}, 2.35$; glucose, 19; and EDTA, 0.5. In addition, to further investigate the iNOS activity as a possible source of the NO production induced by $\mathrm{CT}$ or by $8 \mathrm{Br}$-cAMP, we performed experiments using the specific iNOS inhibitor L-NIL $(0.5 \mu \mathrm{M})(22)$.

NOS expression. NOS expression was estimated by Western blot analysis. Caco- 2 cells were exposed to CT $\left(6 \times 10^{-8} \mathrm{M}\right)$ or to $8 \mathrm{Br}$-cAMP $(0.1 \mathrm{mM})$ for 1,6 , and $24 \mathrm{~h}$. Cells were then scraped into PBS buffer and lysed in the following buffer $(\mathrm{KCl}$, $60 \mathrm{mM}$; $\beta$-mercaptoethanol, $14 \mathrm{mM}$; EDTA, $2 \mathrm{mM}$; HEPES, $\mathrm{pH} 7.9,15 \mathrm{mM}$; sucrose, $0.3 \mathrm{M}$; aprotinin, $5 \mu \mathrm{g} / \mathrm{mL}$; leupeptin, $10 \mu \mathrm{g} / \mathrm{mL}$; pepstatin, $2 \mu \mathrm{g} / \mathrm{mL}$; phenylmethylsulfonyl fluoride, $0.1 \mathrm{mM}$ ) containing $1 \%$ Tergitol (Nonidet P-40). Total extracts were centrifuged at $1500 \times g$ for $20 \mathrm{~min}$ at $4^{\circ} \mathrm{C}$. Protein content was determined by the Bradford method (Bio-Rad Laboratories, Munich, Germany). The supernatant containing the solubilized proteins was boiled for $5 \mathrm{~min}$ in Laemmli buffer $(62.5$ $\mathrm{mM}$ Tris-HCl, $\mathrm{pH} \mathrm{6.8,} \mathrm{2 \%} \mathrm{SDS,} \mathrm{10 \%} \mathrm{glycerol,} \mathrm{5 \%} \mathrm{2-mercapto-}$ ethanol, and $0.001 \%$ bromophenol blue). Cell protein $(50 \mu \mathrm{g} /$ lane) was added to SDS-PAGE and transferred to a nitrocellulose membrane (BioBlot-NC-Costar; Corning Incorporated, Canada). Blots were blocked with T-TBS buffer (Tris-HCl, $\mathrm{pH} 8.8,10 \mathrm{mM}$; $\mathrm{NaCl}, 150 \mathrm{mM}$; Tween 20, 0.05\%) containing 3\% albumin, and probed for $1 \mathrm{~h}$ with affinity-purified anti-human NOS 1 (1:2000), NOS 2 (1:200), or NOS 3 (1:1000) rabbit polyclonal antibodies. Bound antibody was detected with anti-rabbit immunoglobulin 
horseradish peroxidase-linked whole antibody and developed by chemiluminescence reaction (Amersham Pharmacia Biotech, U.K.). All incubations and washes were carried out at room temperature with gentle shaking.

$\gamma$-Interferon $(50,000 \mathrm{U} / \mathrm{mL})$ was used as a positive control in experiments performed using anti-iNOS antibodies, as previously reported (17).

Chemicals. All chemicals were of reagent grade and were obtained from Sigma Chemical Co. (St. Louis, MO, U.S.A.). Culture media were from Life Technologies (GIBCO BRL, Milan, Italy). Transwell filters and supports were from Costar (Costar Italia, Milan, Italy). Anti-cNOS and anti-iNOS polyclonal antibodies were obtained from Santa Cruz Biotechnology (Santa Cruz, CA, U.S.A.). Anti-iNOS polyclonal antibodies were purchased from Transduction Laboratories (ABD Company, Lexington, KY, U.S.A.).

Statistical analysis. All data were expressed as mean \pm SD. Each experiment was run in duplicate and was repeated at least three times. Repeated-measures ANOVA was applied with Bonferroni test for multiple comparisons. The significance was set at $5 \%$.

\section{RESULTS}

Intestinal transport studies. The simultaneous addition of LNAME to both sides of the Caco-2 cell monolayer induced an increase in $I_{\mathrm{sc}}$. The electrical response was slow in the first $35 \mathrm{~min}$, then $I_{\mathrm{sc}}$ increased, with a peak $55 \mathrm{~min}$ after the addition of the NOS inhibitor. The increase in $I_{\mathrm{sc}}$ was totally caused by an effect on PD, as no modifications of $G$ values were recorded. The addition of $\mathrm{CT}$ to the luminal side of the Caco-2 cell monolayer induced a similar increase in $I_{\mathrm{sc}}$, without modifications in $G$. The electrical response was slow in the first $25 \mathrm{~min}$, then $I_{\mathrm{sc}}$ increased, with a peak $35 \mathrm{~min}$ after toxin addition. Preincubation of Caco-2 cells for 5 min with L-NAME produced a further increase of the CT-induced $I_{\mathrm{sc}}$ rise, which was significantly greater than the sum of each individual testing molecule (Fig. 1).

cAMP determination. Intracellular cAMP concentrations were determined after $1 \mathrm{~h}$ of incubation with $\mathrm{CT}$ in the presence or absence of L-NAME. CT induced a 6-fold increase in the basal cAMP intracellular concentration. The addition of L-NAME produced a significant increase in basal cAMP. It also resulted in a further significant increase in CT-stimulated intracellular cAMP concentration. Again, the effect of CT and L-NAME was synergistic, being greater than the sum of each individual effect (Fig. 2).

$\mathrm{NO}_{2}{ }^{-} / \mathrm{NO}_{3}{ }^{-}$concentration. One hour of incubation with $\mathrm{CT}$ induced an increase in NO concentration of approximately 9-fold. The effect was $\mathrm{Ca}^{2+}$-dependent, as the NO increase in response to $\mathrm{CT}$ addition was blunted in the absence of $\mathrm{Ca}^{2+}$. In contrast, preincubation with the specific iNOS inhibitor, L-NIL, did not prevent the CT-induced NO increase (Fig. 3). Similar results were obtained after incubation with the cAMP analog, 8Br-cAMP, as shown in Figure 3. 8Br-cAMP was able to induce a dose- and time-dependent NO production by the enterocyte. The maximal effect was obtained at the concentration of $0.1 \mathrm{mM}$ (Fig. 4) and after $30 \mathrm{~min}$ of incubation (Fig. 5). In this condition NO production did not show a further increase, indicating a saturation of the effect.

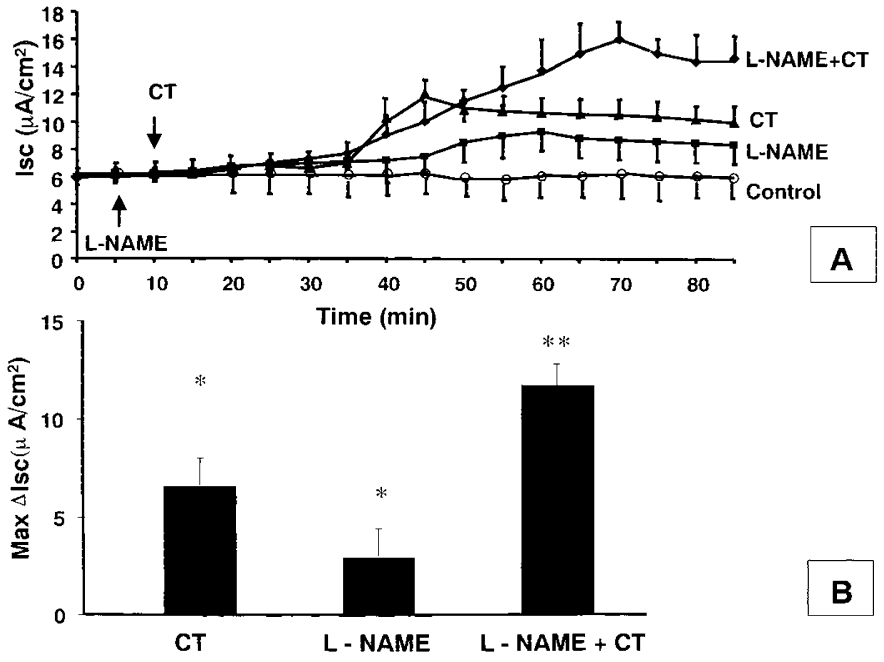

Figure 1. $A$, time course of the effect on $I_{\mathrm{sc}}$ of the CT and L-NAME addition, alone or in combination, to Caco-2 cells mounted in Ussing chambers. Arrows indicate the time of addition of each agent. $B$, maximal $I_{\mathrm{sc}}$ increases after the addition of CT and of L-NAME alone or in combination to Caco-2 cells mounted in Ussing chambers. Data are mean \pm SD of six different observations. ${ }^{*} p<0.05 v s$ control; $* * p<0.05 v s$ L-NAME or CT alone.

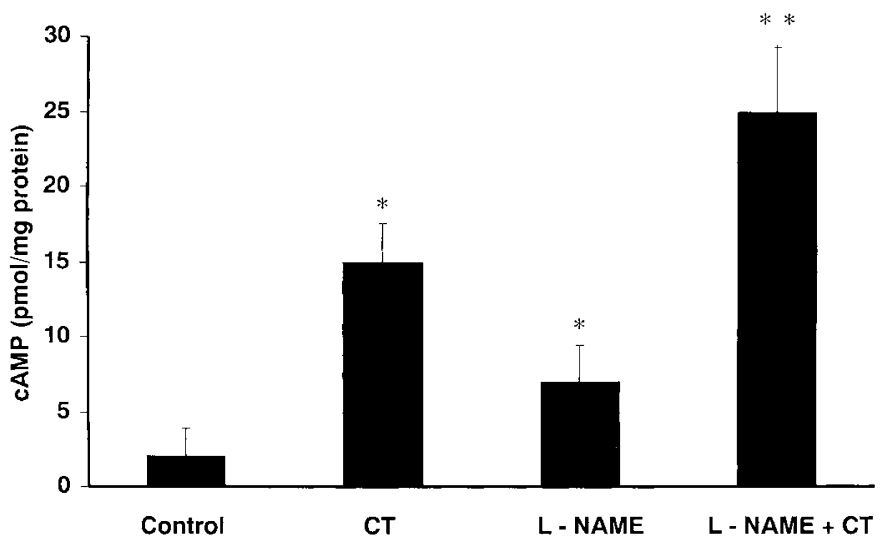

Figure 2. Modifications of the intracellular cAMP concentration in Caco-2 cells after $1 \mathrm{~h}$ of incubation with CT and L-NAME, alone or in combination. Data are mean $\pm \mathrm{SD}$ of six different observations. ${ }^{*} p<0.05 v$ s control; $* * p<0.05 v s$ L-NAME or CT alone.

NOS expression. Because L-NAME is a nonselective inhibitor of NOS (2), experiments were performed to assess the precise identity of NOS involved using Western blot analysis. In basal conditions cNOS (NOS 1) protein expression in Caco-2 cells was negligible, and there was no evidence of the other constitutive (NOS 3) or inducible (NOS 2) forms. Western blot analysis performed after $1 \mathrm{~h}$ of incubation with $\mathrm{CT}$ revealed stimulation of cNOS (NOS 1) protein expression, as shown by the amplification of a $160-\mathrm{kD}$ band that corresponded to human NOS 1 . A similar result was obtained after stimulation with 8Br-cAMP (Fig. 6). Neither CT nor 8BrcAMP was able to elicit NOS 2 or NOS 3 protein expression with up to $24 \mathrm{~h}$ of incubation (data not shown).

\section{DISCUSSION}

Fluid and electrolyte secretion into the intestinal lumen is a process that serves several functions. It promotes optimal 


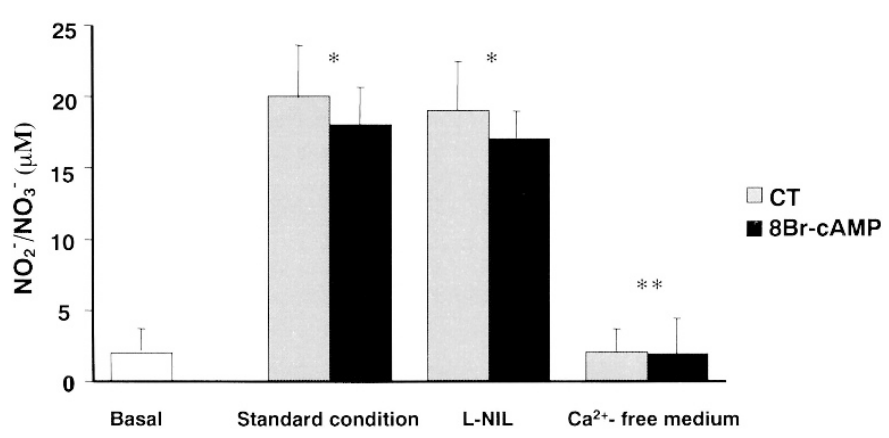

Figure 3. Total NO production in Caco-2 cells determined in basal condition and after stimulation with $\mathrm{CT}$ or $8 \mathrm{Br}-\mathrm{cAMP}$, in standard conditions, in a $\mathrm{Ca}^{2+}$-free medium, and in the presence of the specific iNOS inhibitor, L-NIL. Data are mean \pm SD of six different observations. ${ }^{*} p<0.05$ s basal values; $* * p<0.05$ vs standard condition.

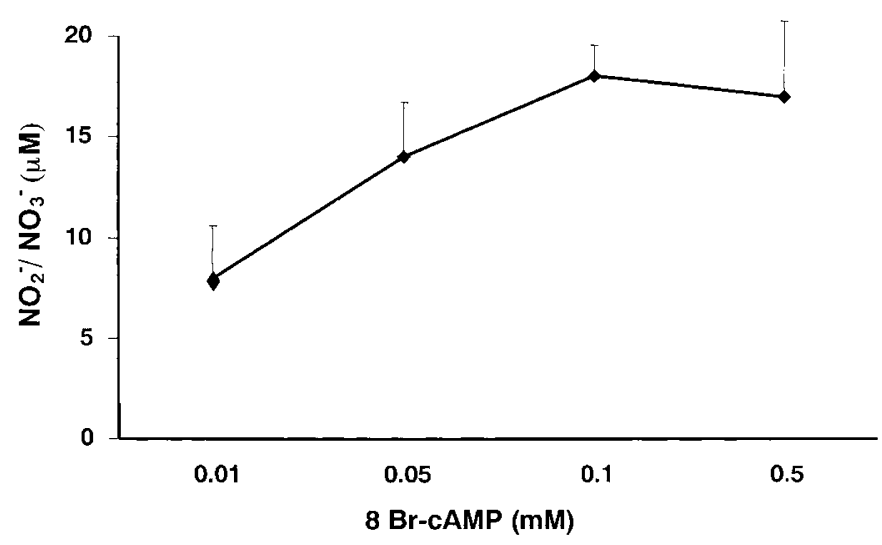

Figure 4. Dose-response relationship of NO production to 8Br-cAMP exposure in Caco-2 cells. Increasing concentrations of $8 \mathrm{Br}$-cAMP were added to Caco-2 cell monolayers, and NO production was determined after $1 \mathrm{~h}$ of incubation. Data are mean \pm SD of six different observations.

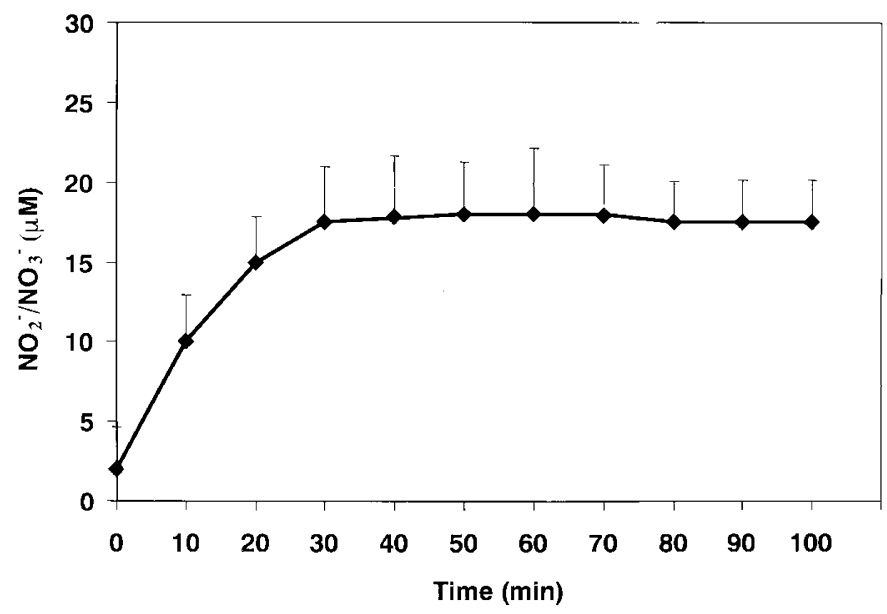

Figure 5. Time course effect of $8 \mathrm{Br}$-cAMP $(0.1 \mathrm{mM})$ addition on NO production in Caco- 2 cells. Data are mean $\pm \mathrm{SD}$ of six different observations.

nutrient digestion and absorption, works in concert with mucins to protect the mucosa, and rids the gut of potentially noxious pathogens and toxins. To prevent excessive fluid losses, water and ions fluxes need to be finely tuned through effective braking mechanism (23). The present study provides evidence for the ability of the enterocyte to limit its own ion

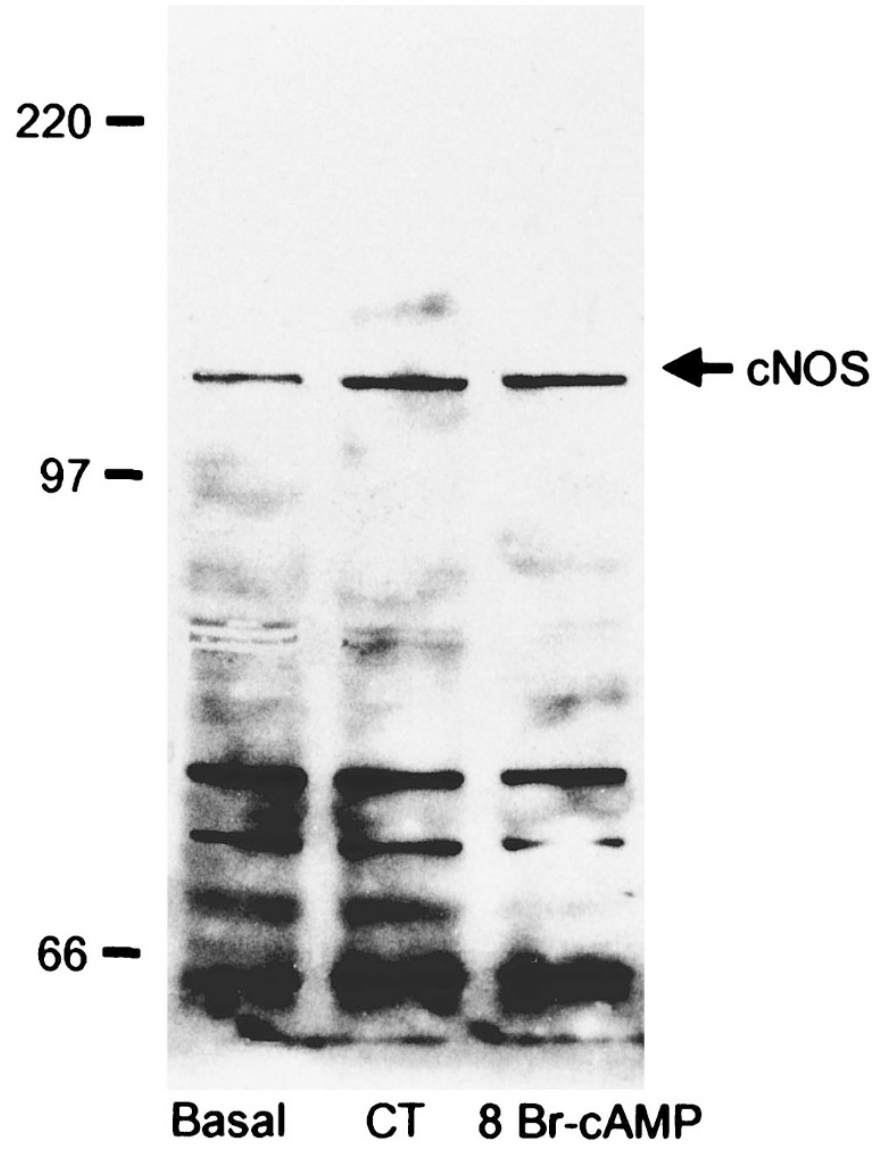

Figure 6. cNOS protein expression in Caco-2 cell monolayers after $1 \mathrm{~h}$ of incubation with CT and 8-Br-cAMP. The cNOS protein expression is revealed by the appearance of a $160-\mathrm{kD}$ band that corresponds to human NOS 1 (neuronal NOS). Shown is a representative of three experiments.

secretion through a mechanism that involves NO. The increase in $I_{\mathrm{sc}}$ elicited by the NOS inhibitor L-NAME suggests that the intracellular NOS concentration produced in the enterocyte is essential to regulate basal transepithelial ion transport. LNAME inhibition of NO production resulted in an increased cAMP concentration and $I_{\mathrm{sc}}$ response, suggesting that in basal conditions NO maintains the intracellular concentration of cAMP at a low level. cAMP could therefore be the target of NO to regulate ion transport in the enterocyte.

The combined addition of CT and of L-NAME resulted in a significant increase in $I_{\mathrm{sc}}$ compared with that obtained with CT alone, suggesting that $\mathrm{NO}$ is also effective in limiting active secretion. Again, the electrical effects were closely linked to cAMP intracellular concentration. Thus a close relationship exists between the modifications of cAMP and the NO effects on ion transport, both in basal conditions and in the presence of active secretion. This may be related to an inhibitory effect by $\mathrm{NO}$ on adenylate cyclase, similar to that described in human monocytes (24).

$\mathrm{NO}_{2}{ }^{-} / \mathrm{NO}_{3}{ }^{-}$determination and Western blot experiments contributed to clarifying the mechanisms of $\mathrm{NO}$ production and its role in response to cAMP-mediated ion secretion. The increased $\mathrm{NO}_{2}{ }^{-} / \mathrm{NO}_{3}{ }^{-}$production in response to $\mathrm{CT}$ or to $8 \mathrm{Br}$-cAMP indicates that $\mathrm{NO}$ synthesis by the enterocyte is increased in response to stimulated secretion. NO overproduction was associ- 
ated with an up-regulation of NOS 1 activity, as suggested by four distinct lines of evidence: 1) the time course of NO production in response to $\mathrm{CT}$ or $8 \mathrm{Br}$-cAMP, whose rapid increase is typical of a cNOS rather than iNOS activity (2);2) the $\mathrm{Ca}^{2+}$ dependence of the effect, again typical of cNOS activity because it is known that the activity of iNOS is $\mathrm{Ca}^{2+}$ /calmodulin-independent (2); 3) the lack of effect elicited by the specific inhibitor of iNOS (L-NIL) on NO production after stimulation with CT or 8Br-cAMP; and 4) the Western blot gels performed with specific anti-cNOS or anti-iNOS antibody, supporting the selective cNOS activation in response to CT or $8 \mathrm{Br}$-cAMP. It has been suggested that upregulation of NOS 1 may be a component of the normal cellular stress response (25). Thus expression levels of the low-output enzymes NOS 1 and NOS 3 may be adjusted to meet local demand (25). Overall these findings are consistent with the concept of self-regulation of ion transport by the enterocyte, which operates in basal condition and, homeostatically, in conditions of stimulated secretion. In vivo evidence supporting the role of $\mathrm{NO}$ in a homeostatic mechanism comes from the increased levels of $\mathrm{NO}$ in both plasma and urine of patients with cholera (26).

Our data are consistent with previous results by Beubler and Schirgi-Degen (27) reporting that i.v. administration of L-NAME enhanced CT-induced ion secretion in rat ligated jejunal loops, whereas the NO precursor L-arginine inhibited it. Similarly inhibition of endogenous NO synthesis by equimolar concentrations of L-NAME caused a secretory response of water and electrolytes in animal models $(2,28,29)$. However, others have reported that the NO substrate L-arginine induced electrogenic secretion in Caco-2 cells (18). These apparently conflicting results may be explained by dose-related phenomena (2). The concentration of L-arginine may play a crucial role in determining the proabsorptive or secretagogue effects. Wapnir et al. (30) have shown that low concentration of L-arginine, added to the oral rehydration solution, stimulates water and electrolyte absorption in the rat jejunum, whereas higher L-arginine concentrations induced a secretory shift of fluid and electrolyte transport. Alternatively, conflicting findings may be related to a species-specific effect of $\mathrm{NO}$ (for example, ileum versus human enterocytes), or to the nature of the specimens used (i.e. whole intestinal tissue, which contains inflammatory, neural, and endocrine-paracrine cells, all potential sources of NO) (31).

The effects of NO in response to CT in Caco-2 cells resemble those observed with other secretagogues including prostaglandin $\mathrm{E}_{2}$, Escherichia coli heat-stable enterotoxin, and Clostridium difficile toxin A (27), and suggest that NO is able to down-regulate fluid secretion elicited by different secretagogues, including those acting through intracellular mechanisms other than cAMP. This may suggest that NO is released in response to cyclic nucleotide concentration.

\section{CONCLUSIONS}

In conclusion, this work provided direct evidence that the enterocyte plays a direct role in the homeostatic regulation of its own ion transport processes, through the activation of the cNOS-NO pathway. This network functions as a braking force of ion secretion both in basal and in cAMP-stimulated condi- tions. The target of this effect is cAMP, which in turn triggers an increase in NOS 1 expression, likely to be interpreted as a homeostatic response.

\section{REFERENCES}

1. Hansen MB, Skadhauge E $1995 \mathrm{New}$ aspects of the pathophysiology and treatment of secretory diarrhoea. Physiol Res 44:61-78

2. Izzo A, Mascolo N, Capasso F 1998 Nitric oxide as a modulator of intestinal water and electrolyte transport. Dig Dis Sci 43:1605-1620

3. Mourad FH, Turvill JL, Farthing MJG 1999 Role of nitric oxide in intestinal water and electrolyte transport. Gut 44:143-147

4. Schirgi-Degen A, Beubler E 1995 Significance of nitric oxide in the stimulation of intestinal fluid absorption in the rat jejunum in vivo. Br J Pharmacol 114:13-18

5. Ignarro LS 1991 Signal transduction mechanisms involving nitric oxide. Biochem Pharmacol 41:485-490

6. Kubes P 2000 Inducible nitric oxide synthase: a little bit of good in all of us. Gut 47:6-9

7. Stefano GB, Salzet M, Magazine HI, Bilfinger TB 1998 Antagonism of LPS and IFN-gamma induction of iNOS in human saphenous vein endothelium by morphine and anandamide by nitric oxide inhibition of adenylate cyclase. J Cardiovasc Pharmacol 31:813-820

8. Lowenstein C, Dinerman J, Snyder S 1994 Nitric oxide, a physiologic messenger. Ann Intern Med 120:227-237

9. Blachier F, Darcy-Vrillon B, Sener A 1991 Arginine metabolism in rat enterocytes. Biochim Biophys Acta 1092:304-310

10. Schirgi-Degen A, Beubler E 1996 Involvement of $\mathrm{K}^{+}$channel modulation in the proabsorptive effect of nitric oxide in the rat jejunum in vivo. Eur J Pharmacol 316:257-262

11. Tepperman BL, Brown JF, Whittle BJR 1993 Nitric oxide synthase induction and intestinal cell viability in rats. Am J Physiol 265:G214-G218

12. Whittle BJR 1994 Nitric oxide in gastrointestinal physiology and pathology. In: Johnson LR (eds) Physiology of the Gastrointestinal Tract, 3rd Ed, Vol 1. Raven, New York, pp 267-294

13. Bosheng Q, Pothoulakis C, Castagliuolo I, Nikulasson Z, Lamont JT 1996 Nitric oxide inhibits rat intestinal secretion by Clostridium difficile toxin A but not Vibrio cholerae enterotoxin. Gastroenterology 111:409-418

14. Turvill JL, Mourad FH, Farthing MJG 1999 Proabsorptive and prosecretory roles for nitric oxide in cholera toxin induced secretion. Gut 44:33-39

15. Salzman AL, Eaves-Pyles T, Linn S, Denenberg AG, Szabò C 1998 Bacterial induction of nitric oxide synthase in cultured human intestinal epithelial cells. Gastroenterology 114:93-102

16. Berni Canani R, Bisceglia M, Bruzzese E, Mallardo G, Guarino A 1999 Growth hormone stimulates through tyrosine kinase, ion transport and proliferation in human intestinal cells. J Pediatr Gastroenterol Nutr 28:315-320

17. Vignoli AL, Srivastava RC, Stammati A, Turco L, Tanori M, Zucco F 2001 Nitric oxide production in Caco-2 cells exposed to different inducers, inhibitors and natural toxins. Toxicol In Vitro 15:289-295

18. Rolfe VE, Milla PJ 1999 Nitric oxide stimulates cyclic guanosine monophosphate production and electrogenic secretion in Caco-2 colonocytes. Clin Sci 96:165-170

19. Guarino A, Berni Canani R, Pozio E, Terracciano E, Albano F, Mazzeo M 1994 Enterotoxic effect of stool supernatant of Cryptosporidium infected calves on human jejunum. Gastroenterology 106:28-34

20. Guarino A, Bisceglia M, Berni Canani R, Boccia MC, Mallardo G 1998 Enterotoxic effect of the vacuolating toxin produced by Helicobacter pylori in Caco-2 cells. J Infect Dis 178:1373-1378

21. Moore PK, Webber RK, Jerome GM, Tjoeng FS, Misko TP, Currie MG 1994 L- $N$-iminoethyl-lysine: a selective inhibitor of inducible nitric oxide synthase. J Med Chem 37:3886-3888

22. Salzman AL, Denemburg AG, Ueta I, O'Connor M, Linn S, Szabò C 1995 Induction and activity of nitric oxide synthase in cultured human intestinal epithelial monolayers. Am J Physiol 270:G565-G573

23. Carey HV 1997 Putting a brake on secretion. Gastroenterology 113:689-690

24. Wang S, Yan L, Wesley RA 1997 Nitric oxide increases tumor necrosis factor production in differentiated U937 cells by decreasing cyclic AMP. J Biol Chem 272:5959-5965

25. Forstermann U, Boisesel JP, Kleinert H 1998 Expressional control of the 'constitutive' isoforms of nitric oxide synthase (NOS I and NOS III) FASEB J 12:773-790

26. Janoff EJ, Hayakawa H, Taylor DN, Fasching CE, Kenner JR 1997 Nitric oxide production during Vibrio cholerae infection. Am J Physiol 73:G1160-G1167

27. Beubler E, Schirgi-Degen A 1997 Nitric oxide counteracts 5-hydroxytryptamine and cholera toxin-induced fluid secretion and enhances the effect of oral rehydration solution Eur J Pharmacol 326:223-228

28. Barry MK, Aloisi JD, Pickering SP, Yeo CJ 1994 Nitric oxide modulates water and electrolyte transport in the ileum. Ann Surg 219:382-388

29. Maher MM, Gontarek JD, Jimenez RE, Cahill PA, Yeo CJ 1995 Endogenous nitric oxide promotes ileal absorption. J Surg Res 58:687-692

30. Wapnir RA, Wingerzahn MA, Teichberg D 1997 L-Arginine in low concentration improves rat intestinal water and sodium absorption from oral rehydration solutions. Gut 40:602-607

31. Mourad FH, O’Dennel LJD, Andre EA, Bearcroft CP, Owen RA, Clark ML, Farthing MJG 1996 L-Arginine, nitric oxide, and intestinal secretion: studies in rat jejunum in vivo. Gut 39:539-544 